\title{
Complexes of adamantine-based group 13 Lewis acids and superacids: bonding analysis and thermodynamics of hydrogen splitting
}

Majid El-Hamdi ${ }^{1}$, Miquel Solà ${ }^{2}$, Jordi Poater ${ }^{3}$ and Alexey Y. Timoshkin ${ }^{1 *}$

1: Inorganic Chemistry Group, Institute of Chemistry, St. Petersburg State University, University pr. 26, Old Peterhof, 198504 St. Petersburg, Russian Federation e-mail: a.y.timoshkin@spbu.ru; majidelhamdi6@gmail.com

2: Institut de Química Computacional i Catàlisi (IQCC) and Departament de Química, Universitat de Girona, Campus Montilivi, E-17071 Girona, Catalonia, Spain e-mail:miquel.sola@udg.edu

3: Department of Theoretical Chemistry and Amsterdam Center for Multiscale Modeling, Vrije Universiteit Amsterdam, De Boelelaan 1083, NL-1081HV Amsterdam, The Netherlands

\begin{abstract}
The electronic structure and chemical bonding in donor-acceptor complexes formed by group 13 element adamantine and perfluorinated adamantine derivatives $\mathrm{EC}_{9} \mathrm{R}^{\prime}{ }_{15}\left(\mathrm{E}=\mathrm{B}, \mathrm{Al} ; \mathrm{R}^{\prime}=\mathrm{H}, \mathrm{F}\right)$ with Lewis bases $\mathrm{XR}_{3}$ and $\mathrm{XC}_{9} \mathrm{H}_{15}\left(\mathrm{X}=\mathrm{N}, \mathrm{P} ; \mathrm{R}=\mathrm{H}, \mathrm{CH}_{3}\right)$ have been studied using energy decomposition analysis (EDA) at the BP86/TZ2P level of theory. Larger stability of complexes with perfluorinated adamantine derivatives is mainly due to better electrostatic and orbital interactions. Deformation energies of the fragments and Pauli repulsion are of less importance, with exception for the boronphosphorus complexes. The MO analysis reveals that LUMO energies of $\mathrm{EC}_{9} \mathrm{R}_{15}$ significantly decrease upon fluorination (by 4.7 and $3.6 \mathrm{eV}$ for $\mathrm{E}=\mathrm{B}$ and $\mathrm{Al}$, respectively) which results in an increase of orbital interaction energies by 27-38 (B) and 15-26 (Al) kcal mol ${ }^{-1}$. HOMO energies of $\mathrm{XR}_{3}$ increase in order $\mathrm{PH}_{3}<\mathrm{NH}_{3}<$ $\mathrm{PMe}_{3}<\mathrm{PC}_{9} \mathrm{H}_{15}<\mathrm{NMe}_{3}<\mathrm{NC}_{9} \mathrm{H}_{15}$. For the studied complexes, there is a linear correlation between the dissociation energy of the complex and the energy difference between HOMO of the donor and the LUMO of the acceptor molecules. The fluorination of the Lewis acid significantly reduces standard enthalpies of the heterolytic hydrogen splitting $\mathrm{H}_{2}+\mathrm{D}+\mathrm{A}=[\mathrm{HD}]^{+}+[\mathrm{HA}]^{-}$. Analysis of the several types of the $[\mathrm{HD}]^{+} \cdot \cdot[\mathrm{HA}]^{-}$ion pair formation reveals that orientation with additional $\mathrm{H} \cdots \mathrm{F}$ interactions is the most favorable energetically. Taking into account the ion pair formation, hydrogen splitting is predicted to be highly exothermic in case of the perfluorinated derivatives. Thus, fluorinated adamantine-based Lewis superacids are
\end{abstract}


attractive synthetic targets and good candidates for the construction of the donoracceptor cryptands.

Keywords: Lewis acids, Boron, Aluminum, 1-boraadamantane, 1-azaadamantane, Donor-acceptor complexes, Hydrogen splitting, Chemical bonding analysis, EDA. 


\section{INTRODUCTION}

Over the past years, the activation of $\mathrm{H}_{2}$ molecule by frustrated Lewis pairs (FLPs) systems has attracted much attention. ${ }^{1}$ Group 13-15 compounds, in particularly, B-P FLP are very active in heterolytic hydrogen splitting. ${ }^{2}$ Nitrogen-containing FLP are less common. ${ }^{1 \mathrm{~d}, \mathrm{e}}$ Nature of the Lewis acid is expected to play a significant role in energetics of the hydrogen splitting. Fluorination of group 13 element aryl derivatives significantly enhances the Lewis acidity. ${ }^{3}$ Computational studies ${ }^{4}$ also reveal importance of pyramidalized environment for the construction of group 13 Lewis superacids. In particular, it was shown that splitting of $\mathrm{H}_{2}$ by donor-acceptor (DA) cryptands, featuring spatially separated donor and acceptor centers with pyramidalized environment, is highly exothermic. ${ }^{\text {4a }}$ However, cryptands designed and computationally considered in a previous work ${ }^{4 \mathrm{a}}$ served only as proof of the concept, since they are still experimentally unknown. A more practical approach should be based on the experimentally known pyramidal donor and acceptor molecules, for example adamantine derivatives. Several heteroatom derivatives of adamantine featuring nitrogen, boron, and silicon atoms have been prepared in the laboratory. ${ }^{5} 1$ boraadamantane, first synthesized in 1983 by Mikhailov et al, ${ }^{6}$ forms complexes with ethylamine, pyridine, and trimethylamine. ${ }^{7}$ Bubnov et al. ${ }^{8}$ reported that reaction of 1 boraadamantane with 1-azaadamantane results in DA complex, which is stable towards atmospheric air and moisture. Due to success of the direct low temperature fluorination, ${ }^{9}$ synthesis of perfluorinated adamantine derivatives also seems viable. Thus, 1-boroadamantane and its fully fluorinated derivatives emerge as viable building blocks for the construction of DA cryptands with pyramidalized group 13 environment. Analysis of the thermodynamics of the hydrogen splitting process is crucial for the correct choice of the Lewis acid-base combination.

In order to choose the best combination of donor and acceptor fragments for the construction of hydrogen splitting cryptands, in the present work we have undertaken a detailed computational study of donor-acceptor complexes formed by group 13 element adamantane and fully fluorinated adamantane derivatives $\mathrm{EC}_{9} \mathrm{R}^{\prime}{ }_{15}$ with nitrogen and phosphorus-containing Lewis bases $\mathrm{XR}_{3}$ and $\mathrm{XC}_{9} \mathrm{H}_{15}\left(\mathrm{E}=\mathrm{B}, \mathrm{Al} ; \mathrm{R}^{\prime}=\mathrm{H}, \mathrm{F} ; \mathrm{X}=\mathrm{N}, \mathrm{P} ; \mathrm{R}\right.$ $\left.=\mathrm{H}, \mathrm{CH}_{3}\right)$ using the generalized gradient approximation (GGA) of density functional theory (DFT) in the form of BP86 functional with all electron TZ2P basis set. 
We present a consistent set of structural data for the studied complexes and report thermodynamic characteristics for their formation and reactions with molecular hydrogen. Results of energy decomposition analyses (EDA) and molecular orbital (MO) features of donor-acceptor complexes are presented. Finally, the influence of the donor and acceptor fragments on the thermodynamics of the heterolytic hydrogen splitting is also discussed. Obtained results can serve as a guideline for the construction of the DA cryptands for the heterolytic hydrogen splitting process.

\section{COMPUTATIONAL DETAILS}

General Procedures. Density functional theory (DFT) calculations were performed with the Amsterdam Density Functional (ADF) program. ${ }^{10}$ The molecular orbitals (MOs) were expanded in a large uncontracted set of Slater type orbitals (STOs) of triple- $\zeta$ quality for all atoms including two sets of polarization functions. ${ }^{11}$ An auxiliary set of s, p, d, f, and g STOs was used to fit the molecular density and to represent the Coulomb and exchange potentials accurately for each SCF cycle. ${ }^{12}$ Energies and gradients were computed using the local density approximation (Slater exchange and VWN correlation) $)^{13}$ with non-local corrections for exchange $\left(\right.$ Becke88) ${ }^{14}$ and correlation (Perdew86) ${ }^{15}$ included self-consistently (i.e. BP86 functional). Analytical Hessians were computed to confirm that optimized geometries correspond to the true minima on the respective potential energy surfaces (PES). Standard enthalpies and entropies were calculated from frequency computations using classical statisticalmechanics relationships for an ideal gas. ${ }^{16}$

Bond Energy Decomposition Analysis. An energy decomposition analysis (EDA) ${ }^{17}$ has been carried out considering the process $\mathrm{D}+\mathrm{A} \rightarrow \mathrm{DA}$ that corresponds to the interaction of donor (D) fragment with acceptor (A) fragment. The complex formation energy $(\Delta \mathrm{E})$ can be written as a sum of two components (eq 1$)$ :

$$
\Delta \mathrm{E}=\Delta \mathrm{E}_{\text {prep }}+\Delta \mathrm{E}_{\text {int }}
$$

In this formula, the preparation energy $\Delta E_{\text {prep }}$ is the amount of energy required to deform the separated donor and acceptor fragments from their equilibrium structures to the geometry that they acquire in the complex. The interaction energy $\Delta E_{\text {int }}$ corresponds to the energy change when the prepared (deformed) fragments are combined to form 
DA complex. It is analyzed in the framework of the Kohn-Sham MO model using a Morokuma-type decomposition of the interaction energy into electrostatic interaction, exchange (or Pauli) repulsion, and orbital interaction terms (eq 2). ${ }^{17 a, e, f}$

$$
\Delta \mathrm{E}_{\text {int }}=\Delta \mathrm{V}_{\text {elstat }}+\Delta \mathrm{E}_{\text {Pauli }}+\Delta \mathrm{E}_{\mathrm{oi}}
$$

The term $\Delta \mathrm{V}_{\text {elstat }}$ is usually attractive. It corresponds to the classical electrostatic interaction between the unperturbed charge distribution of the prepared (deformed) fragments. The Pauli repulsion $\Delta \mathrm{E}_{\text {Pauli }}$ comprises the four-electron destabilizing interactions between occupied MOs. The orbital interaction $\Delta \mathrm{E}_{\mathrm{oi}}$ term accounts for the charge transfer (i.e., donor-acceptor interactions between occupied orbitals on one fragment with unoccupied orbitals of the other, including the HOMO-LUMO interactions) and polarization (empty-occupied orbital mixing on one fragment due to the presence of another fragment).

\section{RESULTS AND DISCUSSION}

Structural and Energetic Features of the Donor-Acceptor complexes. The optimized geometries of the closed-shell singlet ground state of donor-acceptor complexes are shown in Figure 1. All complexes are $\mathrm{C}_{3 v}$ symmetric. Table 1 summarizes selected geometric parameters of the compounds. The Cartesian coordinates of all studied complexes are provided in the Supporting Information. Thermodynamic parameters (standard dissociation enthalpies and entropies) are also given in Table 1, together with dipole moments.

Figure 1 and Table 1

As can be seen from Table 1, dissociation enthalpies of complexes with $\mathrm{BC}_{9} \mathrm{H}_{15}$ are in the range 8.6 to $20.8 \mathrm{kcal} / \mathrm{mol}$. The fluorination of the acceptor moiety dramatically increases the dissociation energy of the boron-containing complexes (by about 40-48 $\mathrm{kcal} \mathrm{mol}^{-1}$ ). For aluminum-containing compounds fluorination effect is smaller than for boron analogs (dissociation energies of the complexes increase by about 22-31 kcal $\left.\mathrm{mol}^{-1}\right)$. Note that all pyramidalized fluorinated boron-containing acceptors form stronger donor-acceptor bonds compared to aluminum analogs \#\#JP: unfluorinated boron acceptors give weaker bonds than aluminium ones from 2.1 to $10.3 \mathrm{kcal} / \mathrm{mol} \#$, which 
reflects higher Lewis acidity of boron-containing pyramidalized Lewis acids. ${ }^{18 c}$ Trends in bond dissociation energies for phosphorus-containing complexes are similar to those of nitrogen analogs. Thus, perfluorinated group 13 adamantine derivatives form the most stable complexes with large dipole moments. Since dissociation energies of complexes of $\mathrm{EC}_{9} \mathrm{~F}_{15}$ are much larger than that of $\mathrm{AlCl}_{3}$, ${ }^{18 \mathrm{a}}$ perfluorinated adamantine derivatives are Lewis superacids in terms of Olah's definition. ${ }^{19}$

On the basis of bond angle-bond distance-bond energy relationship, ${ }^{18 a, b}$ decrease of the $\mathrm{C}-\mathrm{E}-\mathrm{C}$ angle upon complex formation has been previously used as a quantitative indicator for the strength of the unstrained group 13 Lewis acids. However, for the rigid pyramidalized adamantine-type Lewis acids studied in the present work, the structural changes upon complex formation are very small. Fluorination of the acceptor moiety also has little effect on the structural parameters. Upon fluorination, B$\mathrm{X}$ bond distances shorten by $0.066-0.068 \AA$ with the only exception of the $\mathrm{P}\left(\mathrm{CH}_{3}\right)_{3}$ donor (\#MS: Maybe there is an error for this system. Could you please check it?\#), B-C bond lengths increase by 0.003-0.027 $\AA$, and $\mathrm{C}-\mathrm{B}-\mathrm{C}$ angles decrease by about $1.6-3.5^{\circ}$. For aluminium analogues, upon fluorination Al-X bond distances shorten by 0.085 $0.116 \AA$, Al-C bond distances increase by 0.033-0.042 $\mathrm{A}$, and $\mathrm{C}-\mathrm{Al}-\mathrm{C}$ angles decrease by $4.8-5.3^{\circ}$.

\#\#JP: Why are entropies enclosed in Table 1 if they are not discussed? Why not to discuss also Gibbs free energies? Or just to leave deltaS in Table S2 of the SI\#\#

Bonding analysis. In order to understand the origin of the higher stability of complexes of group 13 fluorinated adamantine derivatives we have undertaken an energy decomposition analysis (EDA) of the complexes in their closed shell ground state with respect to isolated fragments (Tables 2 and 3).

Table 2 and Table 3

First, if we focus on the EDA values for boron-containing complexes enclosed in Table 2, it is observed how the total bonding energies $(\Delta \mathrm{E})$ favor fluorinated acceptors by $40.6-50.8 \mathrm{kcal} / \mathrm{mol}$; in line with enthalpies discussed above This difference mainly comes from the interaction energy $\left(\Delta \mathrm{E}_{\text {int }}\right)$, as deformation energies $\left(\Delta \mathrm{E}_{\text {def }}\right)$ only make a maximum difference of $7.4 \mathrm{kcal} / \mathrm{mol}$ in favour of hydrogen-substituted complexes. On the other hand, aluminium complexes present the same trends, but with smaller 
differences (see Table 3). $\Delta \mathrm{E}$ differences are in the range $20.7-32.2 \mathrm{kcal} / \mathrm{mol}$, and $\Delta \mathrm{E}_{\text {def }}$ also favour hydrogenated systems with a maximum difference of $4.5 \mathrm{kcal} / \mathrm{mol}$. Thus, we must go into the decomposition of $\Delta \mathrm{E}_{\text {int }}$ into Pauli, electrostatic and orbital interaction terms in order to get an explanation for the larger strength of the bond formed in fluorinated complexes.

Pauli repulsion does not give a clear trend, thus disfavouring fluorinated complexes with the exception of all B-P complexes and $\mathrm{NH}_{3} \cdot \mathrm{BC}_{9} \mathrm{H}_{15}$. For the same geometry, fluorinated compounds should have larger Pauli repulsion because they have more electrons. Lower Pauli repulsion for fluorinated compounds is attributed to their smaller $\alpha(\mathrm{C}-\mathrm{B}-\mathrm{C})$ angles. In the cases that $\Delta \mathrm{E}_{\text {Pauli }}$ favors the hydrogenated compounds, the contribution of this term to $\Delta \mathrm{E}_{\text {int }}$ is minor, being up to 8.7 and $11.9 \mathrm{kcal} / \mathrm{mol}$ for $\mathrm{B}$ and $\mathrm{Al}$ containing complexes, respectively. Furthermore, in all these cases, both $\Delta \mathrm{V}_{\text {elstat }}$ and $\Delta \mathrm{E}_{\mathrm{oi}}$ terms cause the largest contribution to the higher strength observed in fluorinated compounds. Only for B-P bonded compounds the decrease of Pauli repulsión upon fluorination makes this term more decisive than $\Delta \mathrm{V}_{\text {elstat. Therefore, we }}$ can state that stabilization of boron complexes with perfluorinated derivatives is mainly due a more stabilizing orbital interaction term. The explanation for such is discussed below with the MO interactions of these complexes. On the other hand, as a general trend and compared to boron analogues, aluminium-containing complexes show a significant decrease of the absolute values of $\Delta \mathrm{E}_{\mathrm{oi}}, \Delta \mathrm{V}_{\text {elstat }}$, and $\Delta \mathrm{E}_{\text {Pauli }}$ due to the lengthening of X-Al bond and the lower electronegativity of Al. In general, stabilization of aluminium complexes with perfluorinated derivatives is due to a combination of more favourable $\Delta \mathrm{V}_{\text {elstat }}$ and $\Delta \mathrm{E}_{\mathrm{oi}}$ terms.

\#\#JP: Charges of the front atoms involved in the D-A bond could also help to understand electrostatic interactions\#\#

Molecular Orbitals diagram. With the aim to understand the orbital interactions referred above, the MO diagram for the complex $\mathrm{NC}_{9} \mathrm{H}_{15} \cdot \mathrm{BC}_{9} \mathrm{H}_{15}$ is shown in Figure 2. The MO diagrams for the other complexes are very similar (see HOMO and LUMO energies in Supporting Information). As expected, the interaction between HOMO ($4.49 \mathrm{eV})$ of the donor fragment $\mathrm{NC}_{9} \mathrm{H}_{15}$ and LUMO $(-1.23 \mathrm{eV})$ of the acceptor fragment $\mathrm{BC}_{9} \mathrm{H}_{15}$ leads to the formation of $\sigma$-bonding and $\sigma$-antibonding orbitals. Fluorination of 
the acceptor significantly decreases the energy of the LUMO (by $4.62 \mathrm{eV}$, from -1.23 to $-5.85 \mathrm{eV})$, which enhances the stability of the complex.

\section{Figure 2}

Energy differences between the HOMO of the donor and the LUMO of the acceptor for Al containing compounds are even smaller than for B containing ones; also showing the stabilization caused by fluorination. Thus, such stabilization of the LUMO by fluorination is translated into the larger orbital interactions observed above. \#\#JP: Energies of HOMO of the donor and LUMO of the acceptor in Table S4 maybe could be moved to the manuscript. Even the HOMO-LUMO differences (see table below) should be tabulated, even though you already enclose them in Figure 3\#\#

\begin{tabular}{|c|c|c|c|c|}
\hline $\mathrm{BC}_{9} \mathrm{H}_{15}$ & $\mathrm{BC}_{9} \mathrm{~F}_{15}$ & $\mathrm{AlC}_{9} \mathrm{H}_{15}$ & $\mathrm{AlC}_{9} \mathrm{~F}_{15}$ & \\
\hline-5.05 & -0.43 & -4.33 & -0.74 & $\mathrm{NH}_{3}$ \\
\hline-3.61 & 1.01 & -2.90 & 0.69 & $\mathrm{~N}\left(\mathrm{CH}_{3}\right)_{3}$ \\
\hline-3.26 & 1.36 & -2.54 & 1.05 & $\mathrm{NC}_{9} \mathrm{H}_{15}$ \\
\hline-5.60 & -0.98 & -4.88 & -1.29 & $\mathrm{PH}_{3}$ \\
\hline-4.06 & 0.56 & -3.35 & 0.25 & $\mathrm{P}\left(\mathrm{CH}_{3}\right)_{3}$ \\
\hline-3.86 & 0.76 & -3.14 & 0.45 & $\mathrm{PC}_{9} \mathrm{H}_{15}$ \\
\hline
\end{tabular}

For all studied complexes there is a linear correlation between the energy difference of the HOMO of the donor $\mathrm{E}_{\mathrm{HOMO}}(\mathrm{D})$ and the LUMO of the acceptor $\mathrm{E}_{\mathrm{Lumo}}(\mathrm{A})\left(\mathrm{in} \mathrm{eV}\right.$ ) and the dissociation energy of the complex $\Delta \mathrm{E}^{\mathrm{diss}}$, as can be observed in Figure 3. \#\#JP: I would move the correlation equation to Figure 3\#\# $\Delta \mathrm{E}^{\text {diss }}\left(\mathrm{kcal} \mathrm{mol}^{-1}\right)=(8.35 \pm 0.54)\left\{\mathrm{E}_{\mathrm{HOMO}}(\mathrm{D})-\mathrm{E}_{\mathrm{LUMO}}(\mathrm{A})\right\}+53.1 \pm 1.6 ; \mathrm{R}^{2}=0.91$

Figure 3

\section{Thermodynamics of hydrogen splitting}

Enthalpies of the heterolytic hydrogen splitting in the gas phase (process 3) are summarized in Table 4. Optimized geometries of ionic products of hydrogen splitting are provided in the Supporting Information.

$$
\mathrm{H}_{2}+\mathrm{D}+\mathrm{A}=[\mathrm{HD}]^{+}+[\mathrm{HA}]^{-}
$$

Table 4 
The fluorination of the Lewis acid results in a dramatic decrease of the hydrogen splitting enthalpy by 90.9 and $68.3 \mathrm{kcal} \mathrm{mol}^{-1}$ for compounds containing boron and aluminum, respectively. The influence of group 15 Lewis base is weaker but still pronounced. Thus, substitution of $\mathrm{XH}_{3}$ by $\mathrm{X}\left(\mathrm{CH}_{3}\right)_{3}$ or $\mathrm{XC}_{9} \mathrm{H}_{15}$ results in a decrease of the endothermicity of process 3 by 21.1 and $32.5 \mathrm{kcal} \mathrm{mol}^{-1}$ for $\mathrm{X}=\mathrm{N}$, and by 41.9 and $44.6 \mathrm{kcal} \mathrm{mol}^{-1}$ for $\mathrm{X}=\mathrm{P}$, respectively. Therefore, the enthalpy of the gas phase heterogeneous hydrogen splitting with formation of the isolated ions is endothermic by only $4.3 \mathrm{kcal} \mathrm{mol}^{-1}$ for the best combination of Lewis acid $\mathrm{BC}_{9} \mathrm{~F}_{15}$ and Lewis base $\mathrm{NC}_{9} \mathrm{H}_{15}$.

We have also considered the interaction between gaseous ions $[\mathrm{HD}]^{+}$and $[\mathrm{HA}]^{-}$ with formation of the contact ion pairs. Several possible orientations have been considered for each ion pair (see Supporting information for details). For the nonfluorinated compounds the most stable is the structure featuring dihydrogen bond ${ }^{20}$ (Figure $4 \mathrm{a}$ ). In the case of fluorinated analogues, the most stable is the ion pair in which terminal fluorine atoms are involved in intermolecular H...F interactions (Figure 4b).

Figure 4

It should be noted that for weaker Lewis acids $\mathrm{EC}_{9} \mathrm{H}_{15}$, in several cases, optimization of the contact ion pairs converged to the $\mathrm{H}_{2}$ molecule, indicating favorability of hydrogen evolution. However, in case of perfluorinated acceptors, contact ion pairs have been correctly optimized. The energetics of the ion pair formation (Table 5 \#\#JP: This is the only table that encloses electronic energies instead of enthalpies\#\#) indicates that for the perfluorinated group 13 adamantine derivatives the process of hydrogen splitting $\mathrm{D}+\mathrm{A}+\mathrm{H}_{2}=[\mathrm{HD}]^{+} \cdots[\mathrm{HA}]^{-}$is highly exothermic, even in the gas phase.

\section{Table 5}

As a whole, perfluorinated adamantine-based Lewis acids are predicted to be the most promising candidates for the construction of DA cryptands for hydrogen splitting.

\section{Conclusions}


In this work, we have carried out a comparative computational study of the structural properties, stabilities and reactivities of adamantine-based Lewis acids and their donor-acceptor complexes. Fluorination dramatically decreases the LUMO energy of the acceptor and increases the Lewis acidity, making group 13 perfluorinated adamantine derivatives Lewis superacids. EDA results show that a better orbital interactions are responsible for the larger stability of boron complexes with fluorinated acceptors.In the case of aluminium complexes, the higher stability of the perfluorinated compounds has to be attributed to a combination of more favourable electrostatic and orbital interaction terms. For all studied complexes there is a linear correlation between the energy difference of HOMO of the donor and LUMO of the acceptor molecule and the dissociation energy of the complex.

Fluorination of the Lewis acid has tremendous effect on the hydrogen splitting process. Perfluorinated group 13 adamantine acceptors in combination with $\mathrm{N}$ - and $\mathrm{P}$ containing donors are predicted to exothermically split molecular hydrogen with the formation of the contact ion pairs. Thus, they appear to be attractive synthetic targets as Lewis superacids and good candidates for the construction of spatially separated donoracceptor cryptands.

\section{ACKNOWLEDGMENTS}

This work was financially supported by St. Petersburg State University research grant 12.50.1194.2014. Excellent service of the Centre de Serveis Científiics i Acadèmmics de Catalunya (CESCA) and computer cluster at St. Petersburg State University is gratefully acknowledged. J.P. thanks the Netherlands Organization for Scientific Research (NWO-CW, NWO-EW, NWO-ALW) for financial support. M. S. thanks the following organizations for financial support: the Spanish government (MINECO, project number CTQ2014-54306-P), the Generalitat de Catalunya (project number 2014SGR931, ICREA Academia 2014 prize for excellence in research, and Xarxa de Referència en Química Teòrica i Computacional), and the FEDER fund (European Fund for Regional Development) for the grant UNGI10-4E-801. 
Supporting Information Available. Optimized geometries (Cartesian coordinates in $\AA$ ), total energies, standard enthalpies and entropies for all considered compounds. Energies of HOMO and LUMO for donor (D), acceptor (A), and DA complexes. This material is available free of charge via the Internet http://pub.acs.org.

\section{References}

(1) (a) Stephan, D. W. Org. Biomol. Chem. 2012, 10, 5740; (b) Paradies, J. Angew. Chem., Int. Ed. 2014, 53, 3552; (c) Hounjet, L. J.; Stephan, D. W. Org. Process Res. Dev. 2014, 18, 385; (d) Frustrated Lewis Pairs I. Uncovering and Understanding, Ed. D. W. Stephan, G. Erker, Springer, Top. Curr. Chem. 2013, 332, 1; (e) Frustrated Lewis Pairs II. Expanding the Scope, Ed. D. W. Stephan, G. Erker, Springer, Top. Curr. Chem. 2013, 334, 1; D. W. Stephan, G. Erker Angew. Chem., Int. Ed. 2015 54, 6400.

(2) Welch, G. C.; San Juan, R. R.; Masuda, J. D.; Stephan, D. W. Science. 2006, 314, 1124.

(3) (a) Timoshkin, A. Y.; Frenking, G. Organometallics. 2008, 27, 371; (b) Durfey, B.L.; Gilbert, T.M. Inorg. Chem. 2011, 50, 7871.

(4) (a) Timoshkin, A. Y.; Morokuma, K. Phys. Chem. Chem. Phys. 2012, 14, 14911;

(b) Mück, L. A.; Timoshkin, A. Y.; von Hopffgarten, M.; Frenking, G. J. Am. Chem. Soc., 2009, 131, 3942; (c) Mück, L. A.; Timoshkin, A. Y.; Frenking, G. Inorg. Chem. 2012, 51, 640.

(5) (a) Phillips, D. L.; Gould, I. R.; Verhoven, J. W.; Tittelbach-Helmrich, D.; Myers, A. B. Chem. Phys. Lett. 1996, 258, 87; (b) Dekkers, A. W.; Verhoven, J. W.; Speckam, W. N. Tetrahedron. 1973, 29, 1691; (c) Lilichenko, M.; Verhoven, J. W.; Myers, A. B. Spectrochim. Acta, Part A. 1997, 53, 2079.

(6) Mikhailov, B. M. Pure Appl. Chem. 1983, 55, 1439.

(7) Mikhailov, B. M.; Smirnov, V. N.; Smirnova, O. D.; Kasparov, V. A.; Lagutkin, N. A.; Mitin, N. I.; Zubairov, M. M. Khimiko, Farmatsevticheskii Zhurnal. 1979, 13, 35.

(8) Bubnov, Y. N.; Gurskii, M. E.; Pershin, D. G.; Lyssenko, K. A.; Antipin, M. Y. Russian Chemical Bulletin. 1998, 47, 1771.

(9) Lagow R. J.; Margrave J. L. Prog. Inorg. Chem. 1979, 26, 161.

(10) (a) Baerends, E. J. A., J.; Bérces, A.; Bickelhaupt, F. M.; Bo, C.; de Boeij, P. L.; Boerrigter, P. M.; Cavallo, L.; Chong, D. P.; Deng, L.; Dickson, R. M.; Ellis, D. E.; Fan, L.; Fischer, T. H.; Fonseca Guerra, C.; van Gisbergen, S. J. A.; Groeneveld, J. A.; Gritsenko, O. V.; Grüning, M.; Harris, F. E.; van den Hoek, P.; Jacob, C. R.; Jacobsen, H.; Jensen, L.; van Kessel, G.; Kootstra, F.; van Lenthe, E.; McCormack, D. A.; Michalak, A.; Neugebauer, J.; Osinga, V. P.; Patchkovskii, S.; Philipsen, P. H. T.; Post, D.; Pye, C. C.; Ravenek, W.; Ros, P.; Schipper, P. R. T.; Schreckenbach, G.; Snijders, J. G.; Solà, M.; Swart, M.; Swerhone, D.; te Velde, G.; Vernooijs, P.; Versluis, L.; Visscher, L.; Visser, O.; Wang, F.; Wesolowski, T. A.; van Wezenbeek, E.; Wiesenekker, G.; Wolff, S. K.; Woo, T. K.; Yakovlev, A. L.; Ziegler, T. Amsterdam 2006; (b) te Velde, G.; Bickelhaupt, F. M.; Baerends, E. J.; Fonseca Guerra, C.; van Gisbergen, S. J. A.; Snijders, J. G.; Ziegler, T. J. Comput. Chem. 2001, 22, 931.

(11) Snijders, J. G.; Baerends, E. J.; Vernooijs, P. At. Nucl. Data Tables. 1981, 26, 483. 
(12) Baerends, E. J.; Ellis, D. E.; Ros, P. Chem. Phys. 1973, 2, 41.

(13) Vosko, S. H.; Wilk, L.; Nusair, M. Can. J. Phys. 1980, 58, 1200.

(14) Becke, A. D. Phys. Rev. A. 1988 38, 3098.

(15) Perdew, J. P. Phys. Rev. B. 1986, 33, 8800.

(16) Atkins, P.; De Paula, J. Physical Chemistry; Oxford University Press: Oxford 2006.

(17) (a) Bickelhaupt, F. M.; Baerends, E. J.; Lipkowitz, K. B.; Boyd, D. B. Eds.; Wiley-VCH: New York, 2000; Vol. 15, p 1; (b) Morokuma, K. J. Chem. Phys. 1971, 55, 1236; (c) Morokuma, K. Acc. Chem. Res. 1977, 10, 294; (d) Kitaura, K.; Morokuma, K. Int. J. Quantum Chem. 1976, 10, 325; (e) Ziegler, T.; Rauk, A. Theor. Chim. Acta. 1977, 46, 1; (f) Ziegler, T.; Rauk, A. Inorg. Chem. 1979, 18,1558 .

(18) (a) Timoshkin, A. Y.; Suvorov, A. V.; Bettinger, H. F.; Schaefer, H. F. J. Am. Chem. Soc. 1999, 121, 5687; (b) Davydova, E. I.; Sevastianova, T.N.; Timoshkin, A.Y. Coord. Chem. Rev. 2015, 297-298, 91.

(19) Olah, G. A.; Prakash, G. K. S.; Sommer, J. Science 1979, 206, 13.

(20) Bakhmutov V.I. Dihydrogen bond: Principles, Experiments and Applications. New York: Wiley; 2008. 
Table 1. Selected geometrical parameters (see Figure 1 for a definition of the parameters) of studied complexes (bond lengths $d$ and $r$ in $\AA$ and angles $\alpha$ in degrees), standard dissociation enthalpies $\Delta_{\text {diss }} \mathrm{H}^{\circ}{ }_{298}$ in $\mathrm{kcal} \mathrm{mol}^{-1}$ and standard dissociation entropies $\Delta_{\text {diss }} \mathrm{S}^{\circ}{ }_{298}$ in cal $\mathrm{mol}^{-1} \mathrm{~K}^{-1}$ ), and dipole moments $\mu$ (in Debye). Calculated at the BP86/TZ2P level of theory.

\begin{tabular}{|c|c|c|c|c|c|c|}
\hline Compound & $d(X-E)$ & $\mathrm{r}(\mathrm{E}-\mathrm{C})(\AA)$ & $\alpha(\mathrm{C}-\mathrm{E}-\mathrm{C})$ & $\Delta_{\text {diss }} \mathrm{H}^{\circ} 298$ & $\Delta_{\text {diss }} S^{\circ}{ }_{298}$ & $\mu$ \\
\hline $\mathrm{NH}_{3} \cdot \mathrm{BC}_{9} \mathrm{H}_{15}$ & 1.657 & 1.625 & 110.3 & 17.9 & 37.4 & 5.08 \\
\hline $\mathrm{NH}_{3} \cdot \mathrm{BC}_{9} \mathrm{~F}_{15}$ & 1.591 & 1.628 & 108.7 & 63.0 & 38.2 & 8.07 \\
\hline $\mathrm{N}\left(\mathrm{CH}_{3}\right)_{3} \cdot \mathrm{BC}_{9} \mathrm{H}_{15}$ & 1.732 & 1.635 & 109.2 & 16.3 & 47.6 & 5.07 \\
\hline $\mathrm{N}\left(\mathrm{CH}_{3}\right)_{3} \cdot \mathrm{BC}_{9} \mathrm{~F}_{15}$ & 1.653 & 1.660 & 105.9 & 57.1 & 52.2 & 9.39 \\
\hline $\mathrm{NC}_{9} \mathrm{H}_{15} \cdot \mathrm{BC}_{9} \mathrm{H}_{15}$ & 1.722 & 1.638 & 108.9 & 19.1 & 47.5 & 6.02 \\
\hline $\mathrm{NC}_{9} \mathrm{H}_{15} \cdot \mathrm{BC}_{9} \mathrm{~F}_{15}$ & 1.654 & 1.665 & 105.4 & 60.7 & 52.5 & 11.02 \\
\hline $\mathrm{PH}_{3} \cdot \mathrm{BC}_{9} \mathrm{H}_{15}$ & 1.992 & 1.633 & 110.8 & 8.6 & 34.7 & 3.49 \\
\hline $\mathrm{PH}_{3} \cdot \mathrm{BC}_{9} \mathrm{~F}_{15}$ & 1.955 & 1.635 & 108.9 & 48.6 & 41.1 & 8.37 \\
\hline $\mathrm{P}\left(\mathrm{CH}_{3}\right)_{3} \cdot \mathrm{BC}_{9} \mathrm{H}_{15}$ & 1.973 & 1.643 & 109.5 & 20.2 & 44.0 & 5.51 \\
\hline $\mathrm{P}\left(\mathrm{CH}_{3}\right)_{3} \cdot \mathrm{BC}_{9} \mathrm{~F}_{15}$ & 1.980 & 1.644 & 107.4 & 68.3 & 43.5 & 10.70 \\
\hline $\mathrm{PC}_{9} \mathrm{H}_{15} \cdot \mathrm{BC}_{9} \mathrm{H}_{15}$ & 1.975 & 1.643 & 109.5 & 20.8 & 54.1 & 6.27 \\
\hline $\mathrm{PC}_{9} \mathrm{H}_{15} \cdot \mathrm{BC}_{9} \mathrm{~F}_{15}$ & 1.974 & 1.642 & 107.5 & 69.0 & 49.0 & 12.39 \\
\hline $\mathrm{NH}_{3} \cdot \mathrm{AlC}_{9} \mathrm{H}_{15}$ & 2.087 & 1.985 & 106.7 & 23.2 & 32.1 & 6.34 \\
\hline $\mathrm{NH}_{3} \cdot \mathrm{AlC}_{9} \mathrm{~F}_{15}$ & 2.002 & 2.018 & 101.9 & 48.5 & 34.0 & 12.09 \\
\hline $\mathrm{N}\left(\mathrm{CH}_{3}\right)_{3} \cdot \mathrm{AlC}_{9} \mathrm{H}_{15}$ & 2.084 & 1.991 & 106.0 & 25.2 & 41.6 & 6.38 \\
\hline $\mathrm{N}\left(\mathrm{CH}_{3}\right)_{3} \cdot \mathrm{AlC}_{9} \mathrm{~F}_{15}$ & 1.977 & 2.027 & 100.9 & 53.3 & 37.1 & 13.05 \\
\hline $\mathrm{NC}_{9} \mathrm{H}_{15} \cdot \mathrm{AlC}_{9} \mathrm{H}_{15}$ & 2.065 & 1.993 & 105.7 & 29.4 & 52.9 & 7.67 \\
\hline $\mathrm{NC}_{9} \mathrm{H}_{15} \cdot \mathrm{AlC}_{9} \mathrm{~F}_{15}$ & 1.959 & 2.029 & 100.5 & 59.1 & 43.2 & 15.10 \\
\hline $\mathrm{PH}_{3} \cdot \mathrm{AlC}_{9} \mathrm{H}_{15}$ & 2.587 & 1.984 & 107.2 & 11.9 & 28.4 & 4.84 \\
\hline $\mathrm{PH}_{3} \cdot \mathrm{AlC}_{9} \mathrm{~F}_{15}$ & 2.471 & 2.026 & 101.9 & 34.0 & 45.5 & 12.37 \\
\hline $\mathrm{P}\left(\mathrm{CH}_{3}\right)_{3} \cdot \mathrm{AlC}_{9} \mathrm{H}_{15}$ & 2.517 & 1.995 & 105.7 & 22.8 & 50.3 & 7.36 \\
\hline $\mathrm{P}\left(\mathrm{CH}_{3}\right)_{3} \cdot \mathrm{AlC}_{9} \mathrm{~F}_{15}$ & 2.424 & 2.033 & 100.5 & 52.8 & 46.8 & 15.30 \\
\hline $\mathrm{PC}_{9} \mathrm{H}_{15} \cdot \mathrm{AlC}_{9} \mathrm{H}_{15}$ & 2.517 & 1.995 & 105.5 & 22.9 & 51.6 & 8.45 \\
\hline $\mathrm{PC}_{9} \mathrm{H}_{15} \cdot \mathrm{AlC}_{9} \mathrm{~F}_{15}$ & 2.419 & 2.034 & 100.2 & 54.3 & 55.0 & 17.52 \\
\hline
\end{tabular}


Table 2. Energy decomposition analysis (all values in $\mathrm{kcal} . \mathrm{mol}^{-1}$ ) of boron-containing complexes. Calculated at the BP86/TZ2P level of theory.

\begin{tabular}{|c|c|c|c|}
\hline & $\mathrm{NH}_{3} \cdot \mathrm{BC}_{9} \mathrm{H}_{15}$ & $\mathrm{NH}_{3} \cdot \mathrm{B}\left(\mathrm{C}_{9} \mathrm{~F}_{15}\right)$ & $\Delta^{\mathrm{a}}$ \\
\hline$\Delta \mathrm{E}_{\text {Pauli }}$ & 140.91 & 136.18 & 4.73 \\
\hline$\Delta \mathrm{V}_{\text {elstat }}$ & -92.47 & -107.93 & 15.46 \\
\hline$\Delta \mathrm{E}_{\mathrm{oi}}$ & -80.12 & -107.20 & 27.08 \\
\hline$\Delta \mathrm{E}_{\text {int }}$ & -31.69 & -78.95 & 47.26 \\
\hline$\Delta \mathrm{E}_{\mathrm{def}}$ & 11.58 & 12.17 & -0.59 \\
\hline \multirow[t]{2}{*}{$\Delta \mathrm{E}$} & -20.11 & -66.78 & 46.67 \\
\hline & $\mathrm{N}\left(\mathrm{CH}_{3}\right)_{3} \cdot \mathrm{BC}_{9} \mathrm{H}_{15}$ & $\mathrm{~N}\left(\mathrm{CH}_{3}\right)_{3} \cdot \mathrm{BC}_{9} \mathrm{~F}_{15}$ & \\
\hline$\Delta \mathrm{E}_{\text {Pauli }}$ & 131.20 & 139.92 & -8.72 \\
\hline$\Delta \mathrm{V}_{\text {elstat }}$ & -90.34 & -110.50 & 20.16 \\
\hline$\Delta \mathrm{E}_{\mathrm{oi}}$ & -74.96 & -112.78 & 37.82 \\
\hline$\Delta \mathrm{E}_{\mathrm{int}}$ & -34.10 & -83.35 & 49.25 \\
\hline$\Delta \mathrm{E}_{\mathrm{def}}$ & 16.10 & 23.08 & -6.98 \\
\hline \multirow[t]{2}{*}{$\Delta \mathrm{E}$} & -18.00 & -60.27 & 42.27 \\
\hline & $\mathrm{NC}_{9} \mathrm{H}_{15} \cdot \mathrm{BC}_{9} \mathrm{H}_{15}$ & $\mathrm{NC}_{9} \mathrm{H}_{15} \cdot \mathrm{BC}_{9} \mathrm{~F}_{15}$ & \\
\hline$\Delta \mathrm{E}_{\text {Pauli }}$ & 134.73 & 142.41 & -7.68 \\
\hline$\Delta \mathrm{V}_{\text {elstat }}$ & -93.94 & -114.21 & 20.27 \\
\hline$\Delta \mathrm{E}_{\mathrm{oi}}$ & -78.07 & -116.06 & 37.99 \\
\hline$\Delta \mathrm{E}_{\text {int }}$ & -37.29 & -87.86 & 50.57 \\
\hline$\Delta \mathrm{E}_{\mathrm{def}}$ & 16.66 & 24.04 & -7.38 \\
\hline \multirow[t]{2}{*}{$\Delta \mathrm{E}$} & -20.63 & -63.82 & 43.19 \\
\hline & $\mathrm{PH}_{3} \cdot \mathrm{BC}_{9} \mathrm{H}_{15}$ & $\mathrm{PH}_{3} \cdot \mathrm{BC}_{9} \mathrm{~F}_{15}$ & \\
\hline$\Delta \mathrm{E}_{\text {Pauli }}$ & 133.66 & 123.46 & 10.20 \\
\hline$\Delta \mathrm{V}_{\text {elstat }}$ & -73.21 & -77.72 & 4.51 \\
\hline$\Delta \mathrm{E}_{\mathrm{oi}}$ & -80.88 & -110.75 & 29.87 \\
\hline$\Delta \mathrm{E}_{\text {int }}$ & -20.43 & -65.02 & 44.59 \\
\hline$\Delta \mathrm{E}_{\mathrm{def}}$ & 11.82 & 15.82 & -4.00 \\
\hline \multirow[t]{2}{*}{$\Delta \mathrm{E}$} & -8.61 & -49.20 & 40.59 \\
\hline & $\mathrm{P}\left(\mathrm{CH}_{3}\right)_{3} \cdot \mathrm{BC}_{9} \mathrm{H}_{15}$ & $\mathrm{P}\left(\mathrm{CH}_{3}\right)_{3} \cdot \mathrm{BC}_{9} \mathrm{~F}_{15}$ & \\
\hline$\Delta \mathrm{E}_{\text {Pauli }}$ & 153.91 & 135.72 & 18.19 \\
\hline$\Delta \mathrm{V}_{\text {elstat }}$ & -94.51 & -102.43 & 7.92 \\
\hline$\Delta \mathrm{E}_{\mathrm{oi}}$ & -96.34 & -124.37 & 28.03 \\
\hline$\Delta \mathrm{E}_{\text {int }}$ & -36.93 & -91.08 & 54.15 \\
\hline$\Delta \mathrm{E}_{\mathrm{def}}$ & 16.08 & 20.30 & -4.22 \\
\hline \multirow[t]{2}{*}{$\Delta \mathrm{E}$} & -20.85 & -70.78 & 49.93 \\
\hline & $\mathrm{PC}_{9} \mathrm{H}_{15} \cdot \mathrm{BC}_{9} \mathrm{H}_{15}$ & $\mathrm{PC}_{9} \mathrm{H}_{15} \cdot \mathrm{BC}_{9} \mathrm{~F}_{15}$ & \\
\hline$\Delta \mathrm{E}_{\text {Pauli }}$ & 150.49 & 133.23 & 17.26 \\
\hline$\Delta \mathrm{V}_{\text {elstat }}$ & -91.50 & -99.90 & 8.40 \\
\hline$\Delta \mathrm{E}_{\mathrm{oi}}$ & -94.97 & -124.08 & 29.11 \\
\hline$\Delta \mathrm{E}_{\text {int }}$ & -35.98 & -90.75 & 54.77 \\
\hline$\Delta \mathrm{E}_{\mathrm{def}}$ & 15.76 & 19.75 & -3.99 \\
\hline$\Delta \mathrm{E}$ & -20.22 & -71.00 & 50.78 \\
\hline
\end{tabular}

${ }^{\text {a }}$ The difference between values for fluorinated and non-fluorinated acceptors. 
Table 3. Energy decomposition analysis (in kcal.mol ${ }^{-1}$ ) of $\mathrm{XR}_{3}-\mathrm{AlC}_{9} \mathrm{R}_{15}^{\prime}$ and $\mathrm{XC}_{9} \mathrm{H}_{15}-$ $\mathrm{AlC}_{9} \mathrm{R}_{15}^{\prime}$ complexes with $\left(\mathrm{X}=\mathrm{N}, \mathrm{P} ; \mathrm{R}=\mathrm{H}, \mathrm{CH}_{3} ; \mathrm{R}^{\prime}=\mathrm{H}, \mathrm{F}\right)$. Calculated at the BP86/TZ2P level of theory.

\begin{tabular}{|c|c|c|c|}
\hline & $\mathrm{NH}_{3} \cdot \mathrm{AlC}_{9} \mathrm{H}_{15}$ & $\mathrm{NH}_{3} \cdot \mathrm{AlC}_{9} \mathrm{~F}_{15}$ & $\Delta^{\mathrm{a}}$ \\
\hline$\Delta$ EPauli $_{\text {Pa }}$ & 64.50 & 70.37 & -5.87 \\
\hline$\Delta \mathrm{V}_{\text {elstat }}$ & -61.70 & -77.80 & 16.10 \\
\hline$\Delta \mathrm{E}_{\mathrm{oi}}$ & -29.87 & -45.30 & 15.43 \\
\hline$\Delta \mathrm{E}_{\text {int }}$ & -27.07 & -52.73 & 25.66 \\
\hline$\Delta \mathrm{E}_{\mathrm{def}}$ & 1.99 & 2.31 & -0.32 \\
\hline \multirow[t]{2}{*}{$\Delta \mathrm{E}$} & -25.08 & -50.42 & 25.34 \\
\hline & $\mathrm{N}\left(\mathrm{CH}_{3}\right)_{3} \cdot \mathrm{AlC}_{9} \mathrm{H}_{15}$ & $\mathrm{~N}\left(\mathrm{CH}_{3}\right)_{3} \cdot \mathrm{AlC}_{9} \mathrm{~F}_{15}$ & \\
\hline$\Delta \mathrm{E}_{\text {Pauli }}$ & 76.30 & 87.19 & -10.89 \\
\hline$\Delta \mathrm{V}_{\text {elstat }}$ & -71.82 & -90.51 & 18.69 \\
\hline$\Delta \mathrm{E}_{\mathrm{oi}}$ & -34.70 & -57.92 & 23.22 \\
\hline$\Delta \mathrm{E}_{\text {int }}$ & -30.22 & -61.24 & 31.02 \\
\hline$\Delta \mathrm{E}_{\text {def }}$ & 3.61 & 5.41 & -1.80 \\
\hline \multirow[t]{2}{*}{$\Delta \mathrm{E}$} & -26.61 & -55.83 & 29.22 \\
\hline & $\mathrm{NC}_{9} \mathrm{H}_{15} \cdot \mathrm{AlC}_{9} \mathrm{H}_{15}$ & $\mathrm{NC}_{9} \mathrm{H}_{15} \cdot \mathrm{AlC}_{9} \mathrm{~F}_{15}$ & \\
\hline$\Delta \mathrm{E}_{\text {Pauli }}$ & 79.69 & 91.56 & -11.87 \\
\hline$\Delta \mathrm{V}_{\text {elstat }}$ & -76.39 & -97.07 & 20.68 \\
\hline$\Delta \mathrm{E}_{\mathrm{oi}}$ & -36.71 & -61.58 & 24.87 \\
\hline$\Delta \mathrm{E}_{\text {int }}$ & -33.41 & -67.08 & 33.67 \\
\hline$\Delta \mathrm{E}_{\mathrm{def}}$ & 3.93 & 5.88 & -1.95 \\
\hline \multirow[t]{2}{*}{$\Delta \mathrm{E}$} & -29.48 & -61.20 & 31.72 \\
\hline & $\mathrm{PH}_{3} \cdot \mathrm{AlC}_{9} \mathrm{H}_{15}$ & $\mathrm{PH}_{3} \cdot \mathrm{AlC}_{9} \mathrm{~F}_{15}$ & \\
\hline$\Delta \mathrm{E}_{\text {Pauli }}$ & 43.37 & 52.02 & -8.65 \\
\hline$\Delta \mathrm{V}_{\text {elstat }}$ & -32.42 & -44.39 & 11.97 \\
\hline$\Delta \mathrm{E}_{\mathrm{oi}}$ & -25.06 & -45.39 & 20.33 \\
\hline$\Delta \mathrm{E}_{\text {int }}$ & -14.11 & -37.77 & 23.66 \\
\hline$\Delta \mathrm{E}_{\mathrm{def}}$ & 2.22 & 5.18 & -2.96 \\
\hline \multirow[t]{2}{*}{$\Delta \mathrm{E}$} & -11.89 & -32.59 & 20.70 \\
\hline & $\mathrm{P}\left(\mathrm{CH}_{3}\right)_{3} \cdot \mathrm{AlC}_{9} \mathrm{H}_{15}$ & $\mathrm{P}\left(\mathrm{CH}_{3}\right)_{3} \cdot \mathrm{AlC}_{9} \mathrm{~F}_{15}$ & \\
\hline$\Delta \mathrm{E}_{\text {Pauli }}$ & 59.98 & 69.77 & -9.79 \\
\hline$\Delta \mathrm{V}_{\text {elstat }}$ & -52.56 & -72.57 & 20.01 \\
\hline$\Delta \mathrm{E}_{\mathrm{oi}}$ & -34.38 & -59.75 & 25.37 \\
\hline$\Delta \mathrm{E}_{\text {int }}$ & -26.96 & -62.55 & 35.59 \\
\hline$\Delta \mathrm{E}_{\text {def }}$ & 4.42 & 8.94 & -4.52 \\
\hline \multirow[t]{2}{*}{$\Delta \mathrm{E}$} & -22.54 & -53.61 & 31.07 \\
\hline & $\mathrm{PC}_{9} \mathrm{H}_{15} \cdot \mathrm{AlC}_{9} \mathrm{H}_{15}$ & $\mathrm{PC}_{9} \mathrm{H}_{15} \cdot \mathrm{AlC}_{9} \mathrm{~F}_{15}$ & \\
\hline$\Delta \mathrm{E}_{\text {Pauli }}$ & 58.58 & 68.45 & -9.87 \\
\hline$\Delta \mathrm{V}_{\text {elstat }}$ & -51.02 & -70.64 & 19.62 \\
\hline$\Delta \mathrm{E}_{\mathrm{oi}}$ & -34.50 & -61.09 & 26.59 \\
\hline$\Delta \mathrm{E}_{\text {int }}$ & -26.94 & -63.29 & 36.35 \\
\hline$\Delta \mathrm{E}_{\mathrm{def}}$ & 4.41 & 8.58 & -4.17 \\
\hline$\Delta \mathrm{E}$ & -22.53 & -54.71 & 32.18 \\
\hline
\end{tabular}

a The difference between values for fluorinated and non-fluorinated acceptors. 
Table 4. Standard enthalpies $\Delta \mathrm{H}^{\circ}{ }_{298}$ (in $\mathrm{kcal} \mathrm{mol}{ }^{-1}$ ) for the reaction of heterolytic hydrogen splitting by Lewis acids (LA) and Lewis bases (LB) with formation of isolated $[\mathrm{HD}]^{+}$and $[\mathrm{HA}]^{-}$ions in the gas phase (process 3 ). Calculated at the BP86/TZ2P level of theory.

\begin{tabular}{lccc}
\hline LAlLB & $\mathrm{NH}_{3}$ & $\mathrm{~N}\left(\mathrm{CH}_{3}\right)_{3}$ & $\mathrm{NC}_{9} \mathrm{H}_{15}$ \\
\hline $\mathrm{BC}_{9} \mathrm{H}_{15}$ & 127.61 & 106.48 & 95.15 \\
$\mathrm{BC}_{9} \mathrm{~F}_{15}$ & 36.73 & 15.60 & 4.27 \\
$\mathrm{AlC}_{9} \mathrm{H}_{15}$ & 116.33 & 95.20 & 83.87 \\
$\mathrm{AlC}_{9} \mathrm{~F}_{15}$ & 48.05 & 26.92 & 15.59 \\
& & & \\
\hline $\mathrm{LAlLB}$ & $\mathrm{PH}_{3}$ & $\mathrm{P}\left(\mathrm{CH}_{3}\right)_{3}$ & $\mathrm{PC}_{9} \mathrm{H}_{15}$ \\
\hline $\mathrm{BC}_{9} \mathrm{H}_{15}$ & 144.29 & 102.36 & 99.70 \\
$\mathrm{BC}_{9} \mathrm{~F}_{15}$ & 53.41 & 11.48 & 8.82 \\
$\mathrm{AlC}_{9} \mathrm{H}_{15}$ & 133.01 & 91.08 & 88.42 \\
$\mathrm{AlC}_{9} \mathrm{~F}_{15}$ & 64.73 & 22.80 & 20.14 \\
& & & \\
\hline
\end{tabular}

Table 5. Reaction energies $\Delta \mathrm{E}_{0}^{\circ}\left(\mathrm{kcal} \mathrm{mol}^{-1}\right)$ for the heterolytic hydrogen splitting by Lewis acids (LA) and Lewis bases (LB) with formation of contact ion pairs: D + A + $\mathrm{H}_{2}=[\mathrm{HD}]^{+} \ldots[\mathrm{HA}]^{-}$in the gas phase. Data for the most stable ion pair are given. Calculated at the BP86/TZ2P level of theory.

\begin{tabular}{lccc}
\hline $\mathrm{LA} \backslash \mathrm{LB}$ & $\mathrm{NH}_{3}$ & $\mathrm{~N}\left(\mathrm{CH}_{3}\right)_{3}$ & $\mathrm{NC}_{9} \mathrm{H}_{15}$ \\
\hline $\mathrm{BC}_{9} \mathrm{H}_{15}$ & $-^{\mathrm{a}}$ & 3.92 & 2.87 \\
$\mathrm{BC}_{9} \mathrm{~F}_{15}$ & -55.81 & -64.94 & -70.56 \\
$\mathrm{AlC}_{9} \mathrm{H}_{15}$ & $-^{\mathrm{a}}$ & $-^{\mathrm{a}}$ & -4.83 \\
$\mathrm{AlC}{ }_{9} \mathrm{~F}_{15}$ & -41.07 & -48.75 & -53.36 \\
& & & \\
\hline $\mathrm{LA} \backslash \mathrm{LB}$ & $\mathrm{PH}_{3}$ & $\mathrm{P}\left(\mathrm{CH}_{3}\right)_{3}$ & $\mathrm{PC}_{9} \mathrm{H}_{15}$ \\
\hline $\mathrm{BC}_{9} \mathrm{H}_{15}$ & $-^{\mathrm{a}}$ & $-^{\mathrm{a}}$ & $-^{\mathrm{a}}$ \\
$\mathrm{BC}_{9} \mathrm{~F}_{15}$ & -27.91 & -57.07 & -55.95 \\
$\mathrm{AlC}_{9} \mathrm{H}_{15}$ & $-^{\mathrm{a}}$ & $-^{\mathrm{a}}$ & $-^{\mathrm{a}}$ \\
$\mathrm{AlC}_{9} \mathrm{~F}_{15}$ & -10.07 & -40.43 & -39.10
\end{tabular}

${ }^{a}$ Optimization of the contact ion pair converges to the structure with molecular hydrogen molecule $\mathrm{H}_{2}$. 
a)

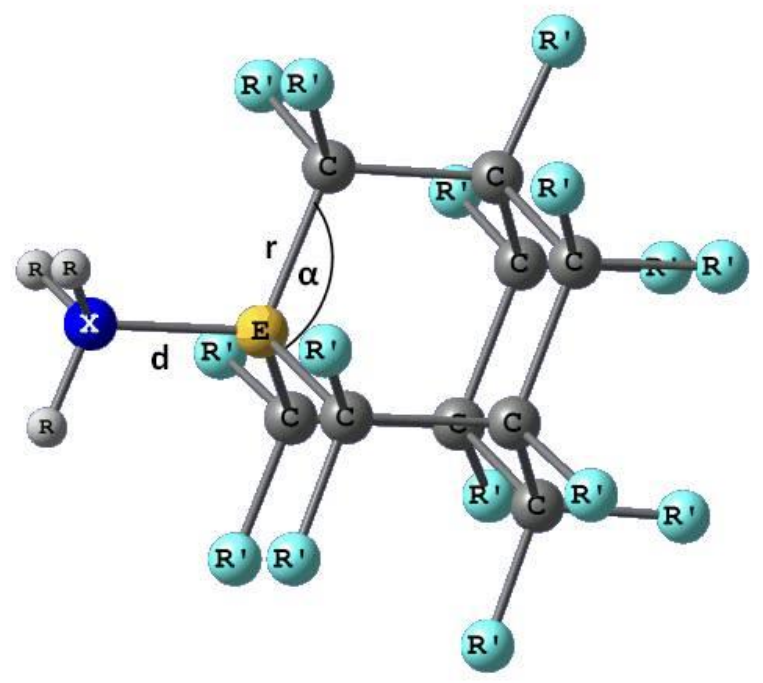

b)

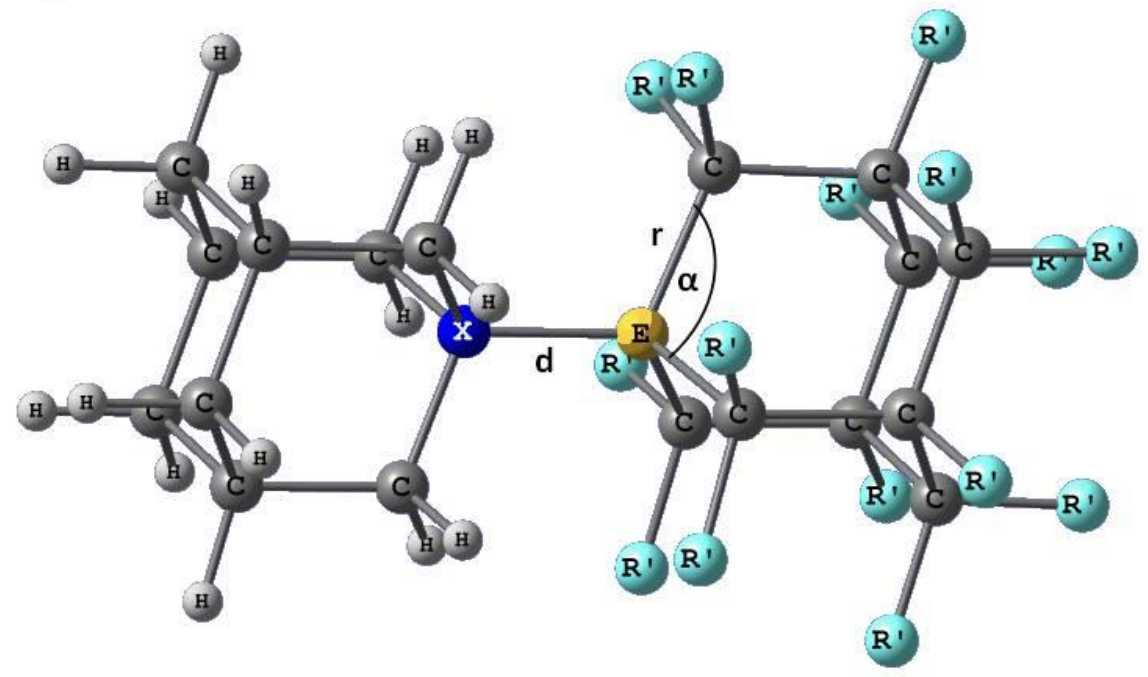

Figure 1. Optimized structures of donor-acceptor complexes: a) $\mathrm{XR}_{3} \cdot \mathrm{EC}_{9} \mathrm{R}_{15}$; b) $\mathrm{XC}_{9} \mathrm{H}_{15} \cdot \mathrm{EC}_{9} \mathrm{R}^{\prime}{ }_{15}\left(\mathrm{X}=\mathrm{N}, \mathrm{P} ; \mathrm{E}=\mathrm{B}, \mathrm{Al} ; \mathrm{R}=\mathrm{H}, \mathrm{CH}_{3} ; \mathrm{R}^{\prime}=\mathrm{H}, \mathrm{F}\right)$. 


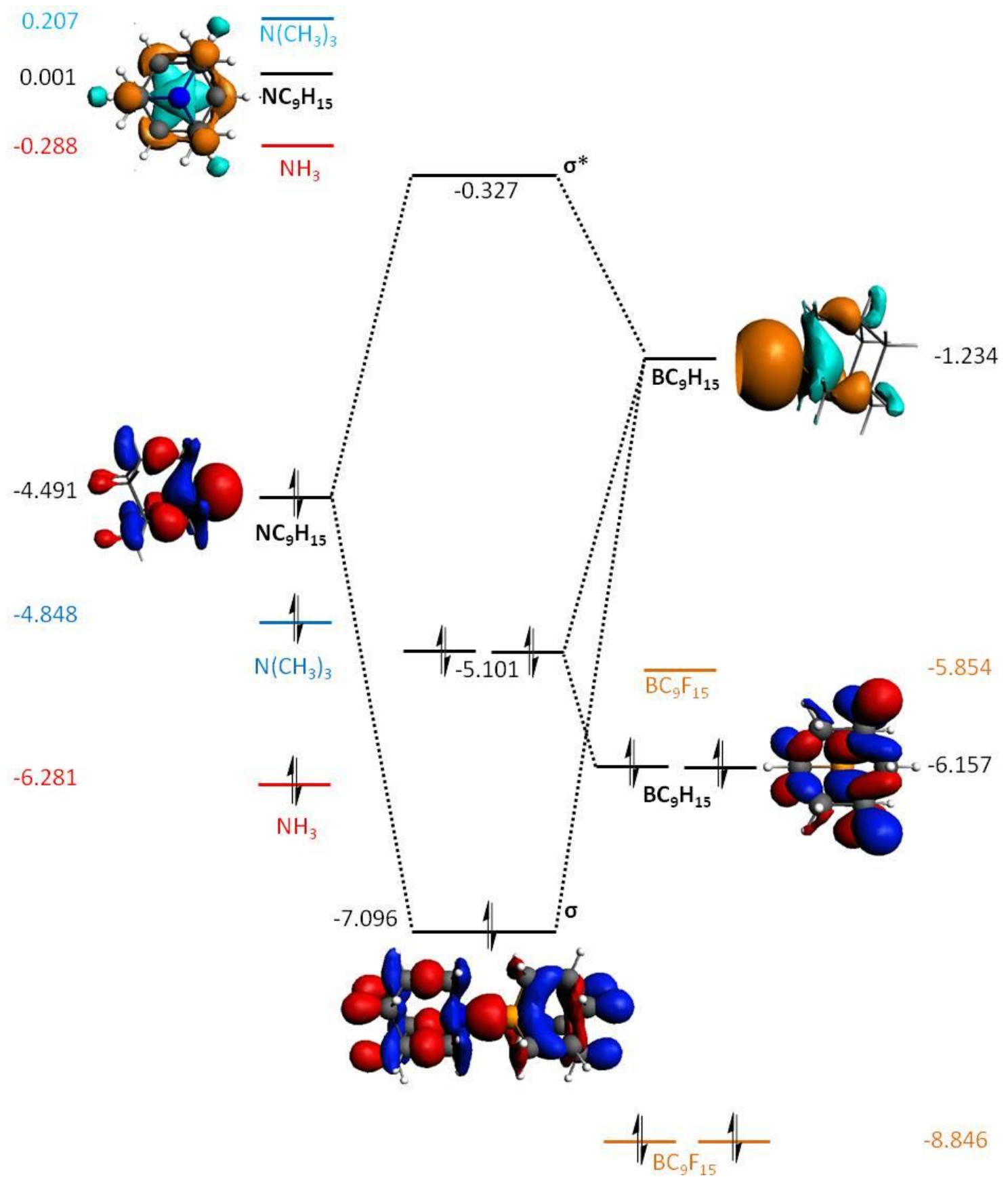

Figure 2. Schematic molecular orbital diagram for $\mathrm{NC}_{9} \mathrm{H}_{15} \cdot \mathrm{BC}_{9} \mathrm{H}_{15}$ complex. Not drawn to scale. HOMO energies of $\mathrm{NH}_{3}, \mathrm{~N}\left(\mathrm{CH}_{3}\right)_{3}, \mathrm{NC}_{9} \mathrm{H}_{15}$ and LUMO and HOMO energies of $\mathrm{BC}_{9} \mathrm{H}_{15}$ and $\mathrm{BC}_{9} \mathrm{~F}_{15}$ are also provided (all values in $\mathrm{eV}$ ). 


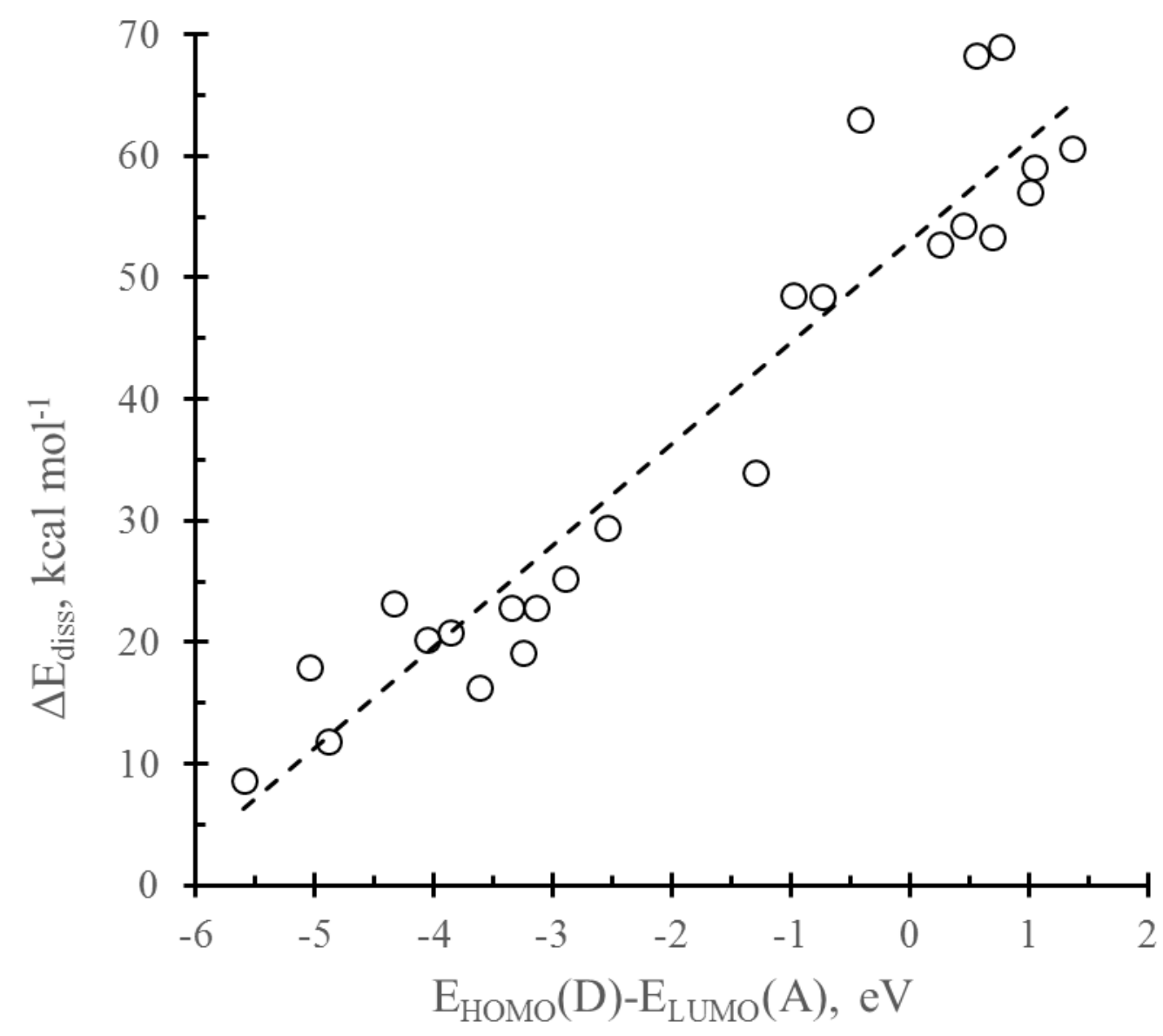

Figure 3. Correlation between the difference of energies of HOMO of donor and LUMO of acceptor molecules and the dissociation energy of the DA complex. \#\#JP: add regression line equation\#\#

(\#In some cases we use $\Delta \mathrm{E}_{\text {diss }}$, in others $\Delta \mathrm{E}^{\text {diss }}$ or $\Delta_{\text {diss }} \mathrm{E}$ and even in some cases $\Delta \mathrm{E}$. Make it uniform otherwise it seems that are different quantities\#) 


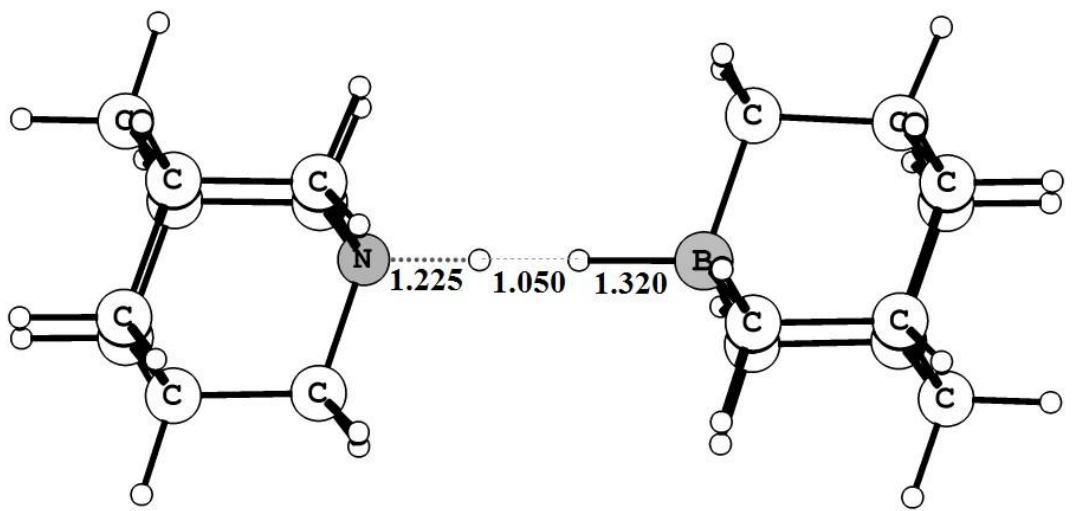

a)

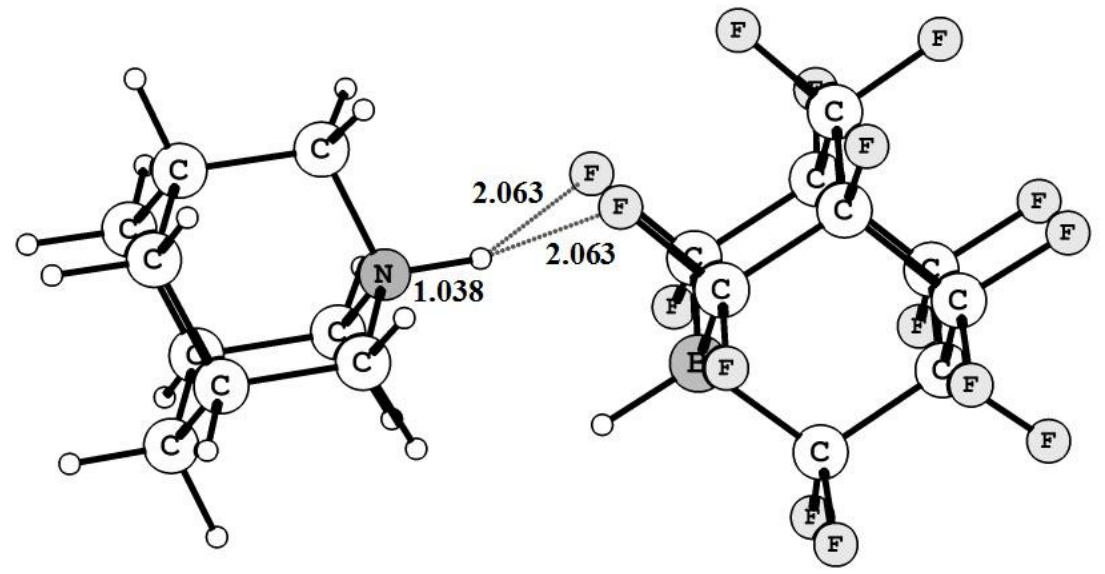

b)

Figure 4. The most stable configurations of the contact ion pairs in case of a) nonfluorinated; and b) perfluorinated Lewis acids. 
Graphic for the Toc

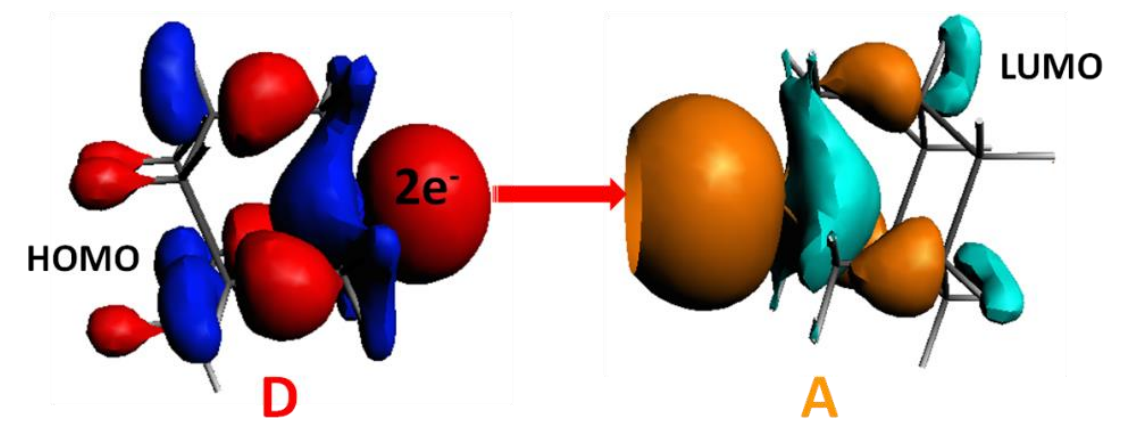

$\Delta \mathrm{E}^{\mathrm{diss}}\left(\mathrm{kcal} \mathrm{mol}^{-1}\right)=(8.35 \pm 0.54)\left\{\mathrm{E}_{\mathrm{HOMO}}(\mathrm{D})-\mathrm{E}_{\mathrm{LUMO}}(\mathrm{A})\right\}+53.1 \pm 1.6 ; \mathrm{R}^{2}=0.91$.

\#\#JP: I would remove the equation, it's not easy to understand\#\# 